\title{
Preliminary Data Examination on Effort Estimation of Resources Needed to Upload Content on Learning Management System (LMS)
}

\author{
Ramya S Gowda, Suma. V
}

\begin{abstract}
Effort Estimation has been a challenging part of e-Learning due to the growing change in technology. E-Learning industry has to meet dynamic requirements of the customer. Content development has to undergo various stages during its development. During the process, initial SLA (Service Level Agreement) varies frequently and there exists several problems in content delivery. Scope Creep is the result of dynamic expectations from the clients without any limitation to the time. This affect the delivery of the product as the resources that were allocated to the development of the product were according to the initial SLA. This paper discusses about parameters that affect the estimation along with resource requirement computation. The paper further focuses on traditional effort estimation technique while analyzing the scope creep life cycle for e-Learning project. The Investigation is made by considering one of the leading middle level e-Learning organization. The case-study and the statistical analysis are carried out on the data which is collected from the company. From the analysis, amount of resource required to handle the dynamic data can be estimated.
\end{abstract}

Key words: Effort, Estimation, E-learning, SLA, Computation.

\section{INTRODUCTION}

In the current era of education, e-Learning has become very effective as "Time to Market is the mantra of the day". Despite of various difficulties in implementing e-Learning in education system it has gained its popularity due to its varied benefits [1]. This is because, education system is continuously evolving and due to the vast change in the model, there is enormous difference that makes e-Learning interesting to students. Learning is the act of acquiring knowledge or skills through study, experience or being taught. With the concept of anytime, anywhere learning, it proves the combined model of pedagogy, technology and accreditation to avail the effectiveness of effort estimation technique [1].

In-order to test the effectiveness of the technique, it is required to know the different parameters that affect the

Revised Manuscript Received on November 11, 2019.

* Correspondence Author

Ramya S Gowda, National Content Head, MagnasoftBIM US Eng., Bangalore, Research Scholar, Bharathiar University, Coimbatore. raashiramya@gmail.com

Suma. V, Dean Research and Industry Incubation Centre, Professor, Department of Information Science and Engineering, Dayananda Sagar College of Engineering, Bangalore, sumavdsce@gmail.com, suma-ise@dayanandasagar.edu implementation of the technique. Each technique has varying parameter from one another [2]. Therefore, knowledge of impact of each parameter on the learning model is one of the key steps to proceed towards effective teaching learning process. However, in this research, for the analysis of e-Learning platform the relevant parameters considered are technology, time, cost and effort [2].

There are various software effort estimation technique out of which only technique such as Best Guess Method, Experience based Method, work break down structure, Delphi Method, Three point Estimation, and Function Point/Test point Analysis were considered for evaluation which better relates to e-Learning domain.

From these techniques, it is observed that different techniques estimates different values and create different projects. The estimation differs with various parameters. However, for a successful content delivery, these parameters are must as they affect the results. Also, Success of the project depends on the satisfaction of the customer which results out of quality content [4]. In order to develop quality content, the service level agreement (SLA) must be clear to both the parties namely vendor and the customer. There will be definite violations from the initial SLAs till the content reach its delivery state which is addressed as scope creep. Scope creep occurs when additional requirements or changes occur to the scope of the project. Scope creep is one of the major factors for the successful content delivery on time [4].

However, domain experts in the industry has introduced various informal solutions to control and manage scope creep such as, perfect documentation, setting up of change control process, creating clear project schedule, verifying the scope with stake holders, and conducting regular meetings with project team. Although most of the above resolutions are part of project management techniques and the results achieved in managing scope creep is yet not appreciable [4].

In addition to all the findings, empirical investigation of many researchers shown existence of several other factors that affects the content delivery such as, time, cost, organization maturity level, standards followed in company, domain proficiency, skill set and experience of personnel, complexity of project, process models, and defect count etc [5][2].

Nevertheless, this paper aims to measure the effectiveness of the content delivery in terms of effort requirement based on scope creep. 


\section{Preliminary Data Examination On Effort Estimation Of Resources Needed To Upload Content On Learning Management System (LMS)}

\section{LITERATURE SURVEY}

There is large amount of effort going on with researchers constantly to attain $100 \%$ success in content delivery in any organizations. Project management comprises of deployment of tools for the success delivery of the content [5]. Therefore, it is always better to identify project management as one of the significant technique for a successful content delivery [6]. According to Heikkila et al. (2015), in order to retain the accuracy in the SLAs, the content development team should have good coordination with the client team by formulating effective plan for the development activities [9].

Though there exists several factors, scope creep is considered as one of the major influencing factors for the success of project [4].

Madhuri and Suma (2013) states in their paper that in order to completely satisfy the clients, it is required to incorporate the change at any point of time during the development of project. They further states in their paper that scope creep is one of the factor that influence the project success and its factors are not just predictable change requests [7]. These statements are supported by researcher Ferreira et al. (2009) who indicate the need of analyzing the change requests and SLA variations [8].

Mirza et al (2013) concludes that with all these efforts to maintain quality of requirements, scope creep do occur in content development cycle [10].

However, in any development cycle, process needs to be implemented. Qureshia et al., (2014) gives the information that process models help the designers in carrying out the design and development of the product [11]. Howard et al. (2008) recommends that the quality of the product should be maintained at every stage of design process itself so that rectifications can be made at the design stage [12].

Furthermore, Rashmi and Suma (2014) have put forth the significance of exploratory testing in addition to common testing techniques in order to ensure quality of software products [13]. Further, Azadeh et al. (2014) state that regression analysis refer to a set of methods by which estimates are made for the model parameters from the knowledge of the values of a given input-output dataset. Integrated model and simulation techniques play an important role [14].

Due to the above mentioned reasons, organizations which are keen on sustainability of quality and customer satisfaction thrive towards implementation of effective life cycle management [15].

All the above papers discuss on project delivery in general irrespective of their domain. To analyse the applicability of these research points in e-Learning domain, many researchers have made an effort to bring out the core perspective of e-Learning.

Asha Unnikrishnan (2016) states that e-Learning is more effective to students as it makes students to develop their problem solving skills, critical thinking, analytical skills and responsibility to learning. It empowers the scheduling for learner, 130rganiza activities, adopt technological tools in the classroom, makes the student responsible for his learning and subject the students to regular evaluation. It helps the students to visualize a single problem in multiple perspective. This improves the innovation power. Role of the instructor shifts to act as a facilitator and facilitates the support to learning activity [16]. In this parameter considered is the effort of the learner and the facilitator.

Jasim Mohammed Atiyah et.al (2015) gives the information on the features of e-Learning. E-learning overcomes the restriction of time and place. Information access is accurate. Self paced learning enhances problem solving skills. E-Learning considers the individual learning capacity of the students. Due to the pedagogy, educational material is designed in such a way that it retains in student's mind. It helps in increasing communication among, student, teacher and peers. It is easy to update the e-content and the access of instructor out of working hours is easier [17]. In this parameter identified is the time and place.

Ibrahim and RadiTulb (2014) recommend that web based learning gives a new direction to both students to students and teacher to student interaction. This direction is often called e-Learning 2.0. They also support the fact that e-Learning reaches geographically across and capable of spreading knowledge to remote areas. E-Learning aimed in flexibility, scalability and rapid deploy ability of web based learning promoting innovation. Learner networks can also be created with the help of innovation in e-Learning. This leads to social media based learning [18]. This supports the fact that as the up-gradation in technology happens with the innovations in the resource type, the benefits of pedagogy increases.

Researchers have compared the students learning among online and face-to-face instructions and conclude that on average, students in online learning conditions performed better than those receiving face-to-face instruction provided variable factors remained constant. Variable factors include the online resource effort and facilitator effort.

M. Tutunea et al (2009) recommends that e-Learning platform provides quick feedback from teachers and reduces the time [19]. Therefore, Learning Management System (LMS) is one of the important factors in e-Learning.

Gennaro Costagliola et al (2008) revealed in their empirical analysis that the effort required to model e-learning processes is not influenced by the experience of the instructional designer with the use of e-learning tools, but it only depends on the size of the developed process [20]. This includes the entire product life cycle and its complexity. To look at the narrow factors, it includes the various parameters of the product development life cycle such as time, cost, change requests, etc [5] [2]. This paper focus on analysing the scope creep life cycle for e-Learning domain.

\section{RESEARCH METHODOLOGY}

Product is the key element in any e-Learning domain. It is clear from the researcher's indications that in every e-Learning system various resources need to be available to the learners for increased performance [19]. The type of the resources varies dynamically from text content 
to video content [21]. Hence, the parameter to analyze the effort estimation varies. Thus, the main objective of this research is to analyze parameters both in terms of quantitative and qualitative parameters which influence estimation of effort using any technique. Quantitative parameters such as platform, software, tools and infrastructure can be measured in values and these values affect the result directly and can be measured. However, Qualitative parameters like interoperability and scope creep affects the result in terms of other quantitative factors such as time and cost.

From the literature survey, it is clear that e-learning depends on software resources which are indicated in Figure 1.1 .

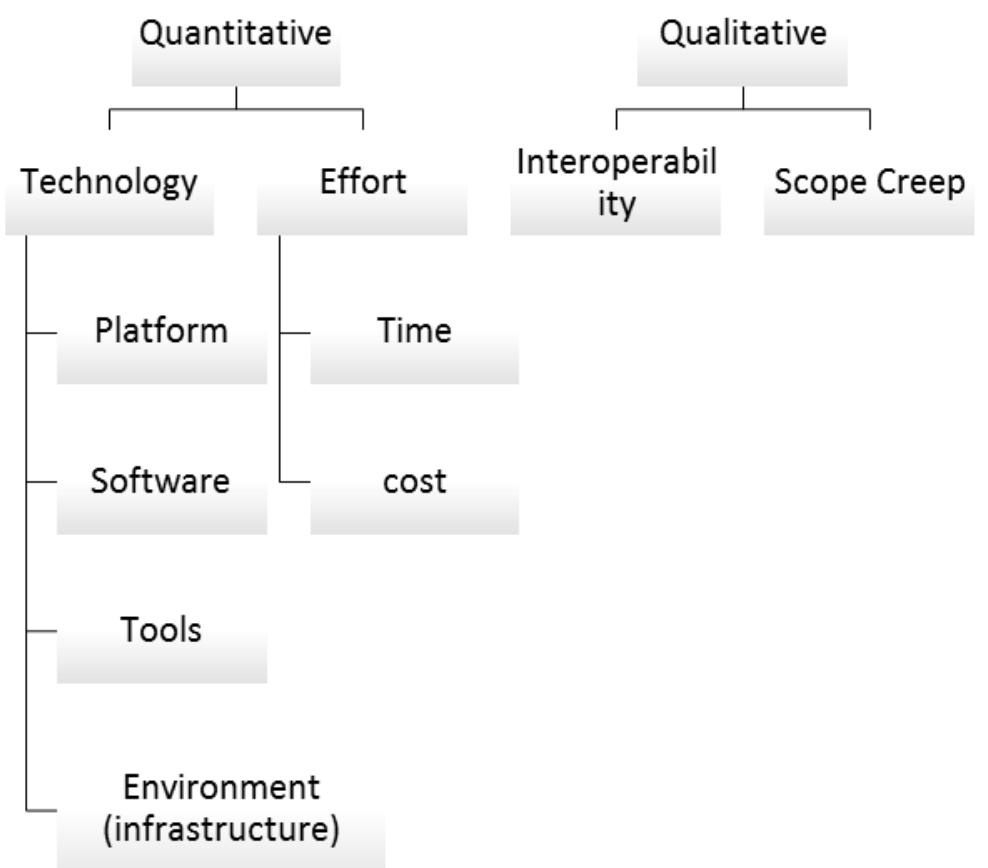

Figure 1: Relationship between various factors that affect the effort estimation in e-Learning

Technological aspects of e-Learning are quantitative parameters such as Technology, Time, Effort and Cost. However, cost and time are in terms of effort itself [1] [4].

Educational information system work together, within and across organizational boundaries to improve the effective delivery of essential e-Learning resources to the students. Because of this interoperability scope creep is created [4]. However, interoperability and scope creep are the qualitative parameters.

In this research, data is collected from the data centers of the middle level e-Learning company for 50 universities. These 50 universities have 4 sessions in a year and data are collected from even semesters 2016-2017 batches for two years. Thus, two excel sheet were prepared for each university, i.e. for semester II and Semester IV for the courses such as BCA, BBA, MCA, and MBA. This paper focuses on analyzing the data given in the excel sheet by selecting only the relevant data such as content development life cycle and delivery date. Therefore, in this paper only 43 universities were considered for analysis considering the common start and end date of the project. The chosen 131rganization is a mid-level company and there are chances of missing out the steps in the content development process. As the accurate content delivery also depends on the factor 'scope creep', this paper is intended to analyze the resource required for the project management which includes scope creep. The intention is to analyze the scope creep life cycle for e-Learning domain [4]. Out of the content from 50 universities, 43 universities were chosen by applying simple random sampling technique considering the common start and end date of content delivery. In order to select the required data from the reports availed, considering 4 types of resources for 2 semesters per year of 4 sessions in 2 years, 48 resources are uploaded. This effort has to be extended for 200 courses.

Data collected from the industries and universities are analyzed manually at the beginning. Trend analysis on the various researches concluded that there are three types of models namely algorithmic model, Non-algorithmic model and machine-learning model [2][3].

From the manual analysis of the reports and the observations, the data for resource requirement, effort calculations and scope creep reasons were drawn. The inference gained is without the change request, 1 resource is specifically required to upload 1 complete course for 2 days. Any additional change requests are considered as scope creep and need to apply scope creep life cycle on the content delivery process [5]. Since, scope creep is inversely proportional to customer satisfaction index, the scope creep can be classified and analyzed by applying the scope creep life cycle [22].

\section{Case Study}

The universities upload content for their respective courses such as BCA, BBA, MCA and MBA. For this research, the content development life cycle for the entire year of 4 sessions for each university is considered. Reports contain the data for various activities in an e-Learning industry. 


\section{Preliminary Data Examination On Effort Estimation Of Resources Needed To Upload Content On Learning Management System (LMS)}

Table 1: Sample Data for content upload on LMS for some university

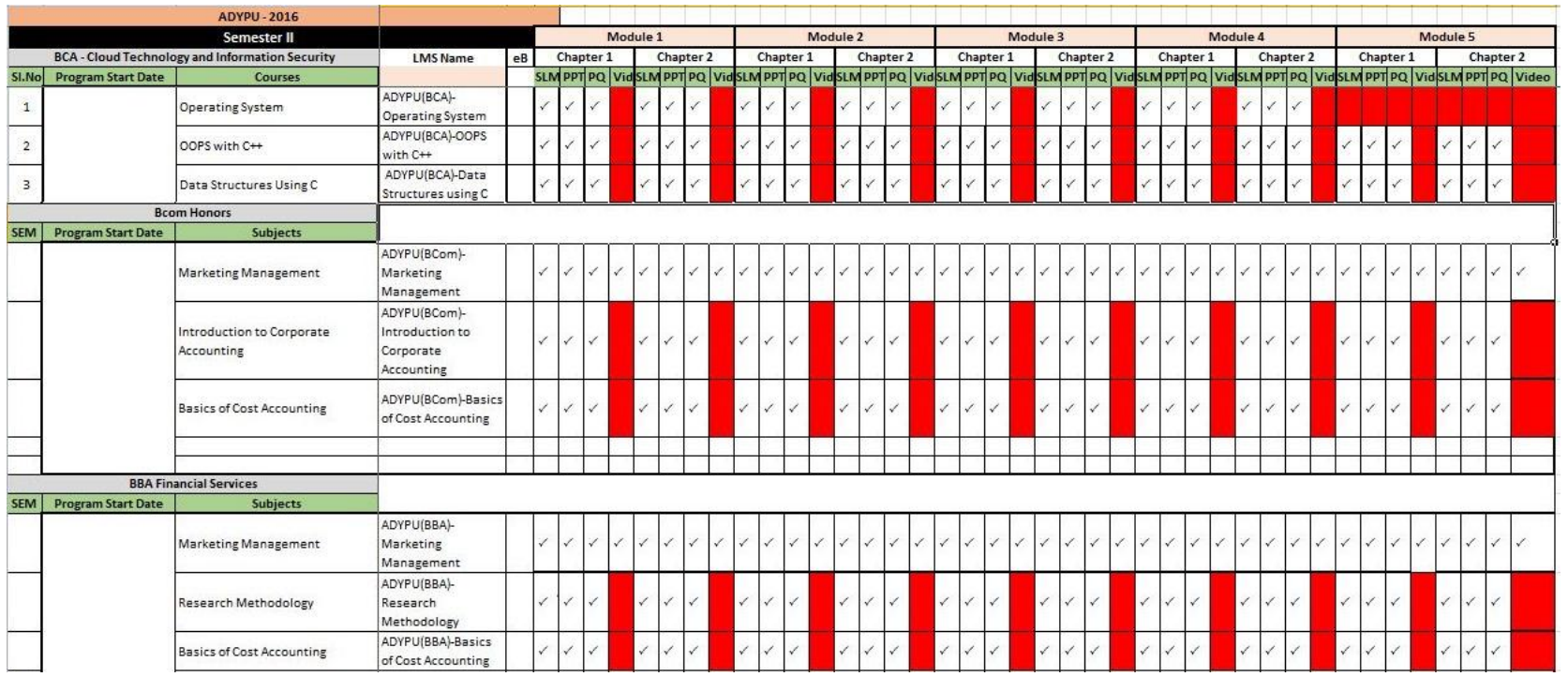

To upload the content for 50 projects, any Learning Management team requires man power. At present, LMS has the team size of four people to manage the e-Learning platform. These facts are obtained manually through the interviewing method from the project manager of the company and these data are analyzed statistically for estimating the effort requirement. Hence, it is observed that for uploading the entire content of 50 universities, one resource is needed for testing, one for gathering business requirement and system analysis, one for managing the webinar sessions, events and announcements, and two resources specifically for content upload on LMS. However, from the reports it is found that the available resources at the company are four who are responsible to perform all the tasks of the LMS. By comparing the required resources and available resources, it is clear that LMS team requires one more resource for the team to fulfill delivery need. Also, the team does not function independently. They often have to depend on their cross functional teams such as content team and product management team for the content. In this case, it is always seen that there are various reason for delays in the process of the cross functional teams which affect content delivery of LMS. Further, cross functional teams also involves interaction with the vendors and clients. During the interaction with the vendors, there are large chances of to and fro transactions in the process of content development. The requirement from the client is an important factor for any business as customer satisfaction is the goal of any business. Frequent changes in the client requests create chaos in the entire process of content development. The change request involves creating additional content, change in the type of the content for the same course, adopting new ways of pedagogy for the old content which the company have already started developing with the old SLAs, etc. In any business which does not follow CMM levels or six sigma, chances of not analyzing the project requirement at the beginning of the project are higher. Due to which there are numerous versions of SLAs till the project reaches its development end cycle. Change in requests at the mid stage of the content development creates chaos in the entire development process which creates scope creep. There should be allotment of the resource again for the change.

However, content needs to be delivered to the client on time. Therefore, analysis is to be made on the various roles to be performed by the LMS team once they receive final content. In the whole process of content development, it is very important to know the basic terminologies of education which is given in the below figure 1.2.

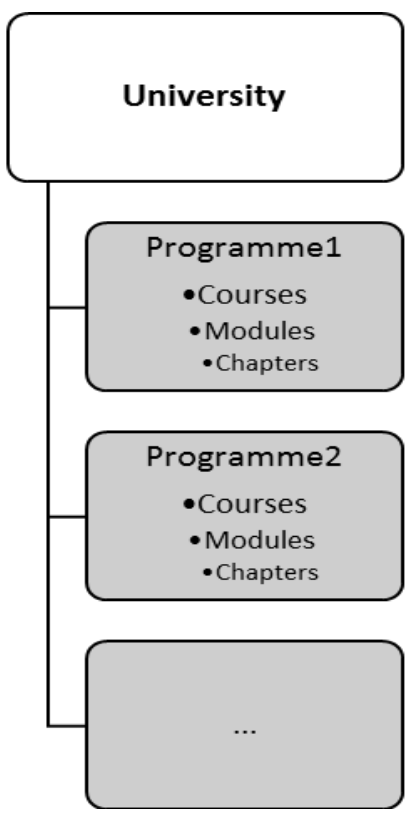

Figure 2: University nomenclatures for programme's and courses [Source., UGC procedures].

From the above figure it is clear that how educational system uses to various terminologies to identify the various components of content. For more clarity, BCA is a programme, the subjects inside BCA are called courses. Each course will have modules which is a collection of chapters. This nomenclature is used universally based on the choice based credit system (CBCS). Any educational organization

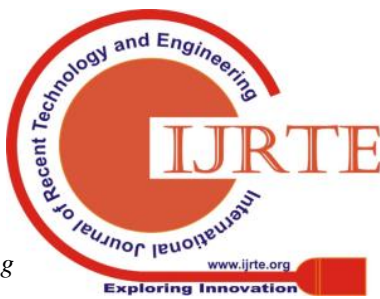


follows CBCS as a regulatory requirement of University Grants Commission (UGC).

At the e-Learning company, the process of uploading involves pre-uploading, uploading and post uploading activities which is done by the LMS team. During the pre-uploading stage, for the sample given in the table considering the 8 courses which has 4 types of content to be uploaded on the LMS by LMS team checks for Nomenclature and creates course instances such as CourseName, CourseFeatures. Therefore, effort to be considered for the uploading of 40 items at a time for one course as one course has 10 chapters.

During the uploading stage, course instance is created, content needs to be uploaded and published. This publishing should be in relation to particular user and the course. One extra post needs to be created for module name. Learning elements needs to be uploaded for each chapter. Once all the content has been uploaded the user has to be assigned to the course or vice-versa is considered as another item.

Therefore, total effort needs to be calculated is the sum of the time required to upload the number of items for each chapter , time required to create a module and the time to create the folder name of the course. It can be represented using the formula in general mathematics as

Total Effort $=$ Time factor for 10 chapters requires 4 items $=$ 4 X $10=40$ items

\section{+ creating a module of 10 items \\ + Create course of 1 item}

Total effort $=$ effort needed for creation of 51 items

Further, there are direct method to create user on the LMS platform which takes 10 minutes for one user and for a batch of 60 users, it requires 600 minutes. In the bulk way/bulk upload, only one user is created which takes 10 minutes and additional 10 minutes to upload. In this case either assign user batch to 1 course or combination of course or vice-versa, it takes the same time. However, every time it cannot be assigned to package as sometimes additional content may needs to be added separately to already created course.

Nevertheless, when we consider actual data considered from the reports for the year 2017 and proposed resource estimation for the year 2018 as shown in table 1.3 and 1.4 respectively, the resource requirement for the LMS team for respective year have been proved using the regression model on the excel sheet.

Table 2: Effort estimation from 2016-March 2017

\begin{tabular}{|c|c|c|c|c|}
\hline Description & course & Requirement in particulars & $\begin{array}{l}\text { Total Time } \\
\text { required }\end{array}$ & $\begin{array}{l}\text { Total resource } \\
\text { required }\end{array}$ \\
\hline $\begin{array}{l}\text { No. Of Unique } \\
\text { Courses }\end{array}$ & 150 & 77 & $\begin{array}{l}154 \text { working } \\
\text { days }\end{array}$ & 4 \\
\hline Events Per month & & 15 & & \\
\hline $\begin{array}{l}\text { Announcements per } \\
\text { month }\end{array}$ & & 15 & & \\
\hline Total courses & 3 & 221 & 442 days & \\
\hline Resource required & & 6 & $\begin{array}{ll}\text { Only } & \text { for } \\
\text { uploading } & \\
\end{array}$ & \\
\hline Addition work & $\bullet$ & $\begin{array}{l}\text { Testing } \\
\text { Requirement gathering } \\
\text { Webex, events, } \\
\text { Announcements }\end{array}$ & $\begin{array}{l}3 \quad \text { resource } \\
\text { required }\end{array}$ & \\
\hline $\begin{array}{l}\text { Total Resource } \\
\text { required for LMS }\end{array}$ & & 9 & $\begin{array}{l}\text { Available team } \\
\text { size }=4\end{array}$ & $\begin{array}{l}\text { New } \\
\text { requirement }=5\end{array}$ \\
\hline
\end{tabular}

In the data for March 2017, total courses considered are three and the total time required for the courses is 442 days considering the facts that one course requires 154 working days with four resources. However, LMS team requires 6 resources only for uploading. Apart from the courses, LMS activity involves creation of testing, requirement gathering, webex, events and announcements for various courses which requires additional 3 resources. Although, With 4 resources, considering 110 working days, it takes 5 months to complete the content delivery. If 6 resources are provided it takes 74 working days i.e., 3 months 8 days to complete the same. Therefore, new requirement for the LMS team are 5 resources. 
Preliminary Data Examination On Effort Estimation Of Resources Needed To Upload Content On Learning Management System (LMS)

Table 1.4 Effort estimation from 2017-March 2018

\begin{tabular}{|l|l|l|l|}
\hline Description & Requirement in particulars & Total Time required & $\begin{array}{l}\text { Total resource } \\
\text { required }\end{array}$ \\
\hline No. Of Unique Courses & $\mathbf{2 0 0}$ & & \\
\hline Events Per month & 15 & & \\
\hline $\begin{array}{l}\text { Announcements per } \\
\text { month }\end{array}$ & 15 & $\mathbf{1 6 0 0}$ days & \\
\hline $\begin{array}{l}\text { Total courses (200 X 4 } \\
\text { items) }\end{array}$ & $\mathbf{8 0 0}$ & & \\
\hline & $\mathbf{7}$ & Only for uploading & \\
\hline Resource required & $\begin{array}{l}\text { Testing } \\
\text { Requirement gathering } \\
\text { Webex,events, Announcements }\end{array}$ & 4 resource required & \\
\hline Addition work & 11 & $\begin{array}{l}\text { Available team size }= \\
6\end{array}$ & New requirement= 5 \\
\hline $\begin{array}{l}\text { Total Resource } \\
\text { required for LMS }\end{array}$ & & & \\
\hline
\end{tabular}

In the proposed data for the year 2018, for 200 unique courses to be delivered on LMS, they require 7 resources only for uploading and it takes 1600days. Additional work requires 4 resources. This year LMS team has 6 resources in hand. It has been proposed by showing with 6 resources it requires 14 months and 10 days considering the working days and with 7 resources it requires 12 months 20 days to complete the content delivery. Although it is not a great affect on the time, still considering the work load and additional work, LMS team requires 11 resources in total. Already the team has 6 resources therefore; resources proposed as new requirement are 5 in number. However, this calculation does not include the change request. Inference is that atleast one dedicated resource is required to deliver one activity in 2 days.

Further, the list of activities performed by the LMS team remains unaltered. However, the quantity of the course content may vary creating a drastic change in the total time taken to upload the content by the LMS team. In most of the reports it is observed that this is caused due to the frequent change in the SLA which results in scope creep. By applying scope creep life cycle on this product, the analysis has to be made that by following the process life cycle one can decrease the delay in the content delivery [5]. Scope creep can be caused due to infrastructure problems or other co-existing features. The first version of SLA may be in conflict with the updated version because of many additional requirements of the project. Consequently, the scope of the system expands.

Applying the scope creep life cycle on the content delivery process of an e-Learning domain, at the first step, the elements of scope creep needs to be identified, classified and the deviations needs to be analyzed. Deviations may be in terms of time, cost and effort. Therefore, impact evaluations have to be conducted through computing the impact of these deviations on cost, schedule and resource requirement for the change. These calculations need to be presented and approved by the clients. Also alternative plan needs to be discussed before obtaining the approval from the client. This has to integrate in the project plan also and all the team members along with vendors need to be communicated regarding the plan change. Each of the activities needs to be tracked monitored and have to be controlled by the project manager and report needs to be done. Finally, these changes need to be implemented in the development while conducting the integrated testing. Finally the approved delivery plan needs to be released for development.

In an e-Learning domain, if the scope creep life cycle is incorporated along with content development life cycle, then one can reduce the maximum delay in the delivery time of the content.

\section{CONCLUSIONS}

E-Learning industry is a growing industry which is a combined result of pedagogy and technology. Pedagogy involves various types of content which needs to delivery through LMS. For a successful content delivery, factors identified to calculate the effort required for content delivery is affected with scope creep. However, Scope creep can be caused due to infrastructure problems or other co-existing features. Other features can be service level agreement features. The chances of failure of the project or wastage of the effort estimated for the project are higher with increased scope creep rate. Factors to the scope creep can be identified and controlled by integrating scope creep life cycle (SCLC) with the content delivery life cycle. An empirical investigation is carried out on the data collected from the mid level e-Learning industry. Several projects of the company were studied and observations were made. Inference is thus made that if the content delivery life cycle is integrated with SCLC, the content delivery failure rates can be reduced. The effort required to upload content on the LMS can be 
analyzed at the beginning by following this process cycle and reduce the time delay. This holds good for e-Learning domain. The drawback of scope creep leads to scope amalgamation.

By applying any analytical testing method, one can devise a mathematical model for effort estimation of resource requirement. Further, by inferring to machine learning techniques accuracy level can be increased so that optimization can be effective.

\section{REFERENCES}

1. Ramya S Gowda, V. Suma, "A Comparative Analysis of Traditional Education System Vs. e-Learning" 2017 International Conference on Innovative Mechanisms for Industry Applications (ICIMIA 2017), Published by IEEE Computer.

2. Ramya S Gowda, V.Suma. 'Review on Various Effort Estimation Techniques', 2017 National Conference on Innovative Practices in Engineering, Sciences and Management - NCIPESM-2017, Journal published and organized by Jupiter Publications Consortium association with National Foundation For Entrepreneurship Development (NFED), Tamilnadu, India

3. P.K. Suri, \& Pallavi Ranjan. (2012), "Comparative Analysis of Software Effort Estimation Techniques", International Journal of Computer Applications (0975 - 8887), Volume 48- No.21.

4. K. Lakshmi Madhuri, Suma V, "Implication of Scope Creep in Software Projects", National Conference On Emerging Research in Technology Of Modern Computing, Applications and Networking", Bangalore, December 27th - 28th 2013.

5. K. Lakshmi Madhuri, Suma V, "Introduction of scope creep life cycle for effective scope creep management in software industries", International Journal of Industrial and Systems Engineering, Vol. 27, No. 4, 2017.

6. Heikkila, V.T., Paasivaara, M., Rautiainen, K., Lassenius, C., Toivola, T. and Jarvinen, J. (2015) 'Operational release planning in large - scale scrum with multiple stakeholders - a longitudinal case study at F- secure corporation', Information and Software Technology, Vol. 57, No. 1, pp.116-140.

7. Madhuri, K.L., Suma, V. and Nair, T.R.G. (2013) 'Factors influencing project success during software development process an analysis', International Journal of Scientific \& Engineering Research, Vol. 4, No. 8, pp.21-26.

8. Ferreira, S., Collofello, J., Shunk, G.M. and Ferreira, S. (2009) 'Understanding the effects of requirements volatility in software engineering by using analytical modeling and software process simulation', The Journal of Systems and Software, Vol. 82, No. 10, pp.1568-1577.

9. Heikkila, V.T., Paasivaara, M., Rautiainen, K., Lassenius, C., Toivola, T. and Jarvinen, J. (2015) 'Operational release planning in large - scale scrum with multiple stakeholders - a longitudinal case study at F - secure corporation', Information and Software Technology, Vol. 57, No. 1, pp.116-140.

10. Mirza, M.N., Pourzolfaghar, Z. and Shahnazari, M. (2013) 'Significance of scope in project success', Procedia Technology, Science Direct, Vol. 9, No. 1, pp.722-729.

11. Qureshia, A.J., Gerickeb, K. and Blessingb, L. (2014) 'Stages in product lifecycle: trans-disciplinary design context', Procedia CIRP 21, Vol. 21, No. 1, pp.224-229.

12. Howard, T.J, Culley, S.J. and Dekoninck, E. (2008) 'Describing the creative design process by the integration of engineering design and cognitive psychology literature', Des. Stud., Vol. 29, No. 2, pp.160-180.

13. Rashmi, N. and Suma, V.(2014) 'Defect detection efficiency of the combined approach', ICT and Critical Infrastructure: Proceedings of the 48th Annual Convention of Computer Society of India, Advances in Intelligent Systems and Computing, Vol. 249, No. 1, pp.485-490.

14. Azadeh, A., Eydi, A., Raoofi, Z. and Rafiei, H. (2014) 'Optimisation of net profit with uncertain inputs in manufacturing environments by integration of neural networks, genetic algorithm and fuzzy regression', Int. J. Industrial and Systems Engineering, Vol. 16, No. 1, pp.88-101.

15. Wolf, M., Pant, R., Chomkhamsri, K., Sala, S. and Pennington. D., (2012) The International Reference Life Cycle Data System [online] http://eplca.jrc.ec.europa.eu/uploads/JRCReference-Report-ILCD-Hand book-Towards-more-sustainable-production-and-consumptionfor-a-reso urce-efficient-Europe.pdf (accessed 1 December 2015).

16. Asha Unnikrishnan (2016) 'E-Learning: An individual Learning Perspective: an Analysis', Int. J. Engineering Research \& Technology (IJERT), Vol. 5, Issue 11, Nov 2016, ISSN:2278-0181.

17. Jasim Mohammed Atiyah, Mohammed M. El Sherbiny, Shawkat K. Guirguis (2015) 'Evaluation of e-Learning Program versus Traditional education Instruction for Undergraduate', Int. J. Advanced Research in Science, Engineering and Technology, Vol. 2, Issue 7, July 2015

18. Ibrahim Albidewi, RadiTulb (2014) 'Promise And Challenge Of e-Learning - Literature Review', European Scientific Journal, Vol. 10, No.1, January 2014. ISSN: 1857-7881 (Print) e-ISSN 1857-7431

19. M. Tutunea, R.V. Rus, V. Toader (2009) 'Traditional Education Vs. e-Learning in the vision of Romanian business students', Int. J. Education And Information Technologies, Vol. 3, Issue 1.

20. Gennaro Costagliola, Andrea De Lucia, Filomena Ferrucci, Carmine Gravino, Giuseppe Scanniello (2008) 'Assessing the usability of a visual tool for the definition of e-Learning processes', Journal of Visual Languages Computing, Vol. 19, Issue 6, December 2008, Pages 721-737.

21. Ramya S Gowda, Suma V (2017), 'Analysis of E-learning Effectiveness In Higher Education' International Conference on Intelligent Sustainable Systems (ICISS 2017), organized by SCAD Institute of Technology, Palladam, India. Published by IEEE Xplore, Conference dates 7-8, December 2017.

22. Dereli, T. and Durmusoglu, A. (2010) 'An integrated framework for new product development using who-when-where-why-what-how $(5 \mathrm{~W} 1 \mathrm{H})$, theory of inventive problem solving, and patent information - a case study', Int. J. Industrial and Systems Engineering, Vol. 5, No. 3, pp.354-365. 